\title{
Decreased mean platelet volume in panic disorder
}

This article was published in the following Dove Press journal:

Neuropsychiatric Disease and Treatment

4 September 2014

Number of times this article has been viewed

\section{Ișıl Göğçegöz Gül \\ Gül Eryılmaz \\ Eylem Özten \\ Gökben Hızlı Sayar}

Neuropsychiatry Health, Practice, and Research Center, Uskudar University, Istanbul, Turkey
Correspondence: Gökben Hızlı Sayar NPİstanbul Hastanesi Alemdağ Cad, Siteyolu Sk No 27, Ümraniye, İstanbul, Turkey

Tel +902166330633

Fax +902166341250

Email gokben.hizlisayar@uskudar.edu.tr
Aim: The relationship between psychological stress and platelet activation has been widely studied. It is well known that platelets may reflect certain biochemical changes that occur in the brain when different mental conditions occur. Platelet 5-hydroxytryptamine (5-HT) is also extensively studied in psychiatry. The mean platelet volume (MPV), the accurate measure of platelet size, has been considered a marker and determinant of platelet function. The aim of the present study was to search for any probable difference in the MPV of subjects with panic disorder (PD).

Methods: A total of 37 drug-free subjects, aged 18 to 65 years, diagnosed with PD, with or without agoraphobia, according to the Diagnostic and Statistical Manual of Mental Disorders, Fourth edition (DSM-IV) criteria and 45 healthy control subjects were included in the study. Platelet count and MPV were measured and recorded for each subject.

Results: There were no statistically significant differences between groups in terms of female/ male ratio, age, or body mass index between the PD group and control group $(P=0.91, P=0.82$, and $P=0.93$, respectively). The MPV was found to be significantly lower in the PD group compared with the control group $(8.8 \pm 0.9 \mathrm{fL}$ vs $9.2 \pm 0.8 \mathrm{fL} ; P=0.02)$. All the participants had MPV values in the standard range of 6.9-10.8 fL.

Conclusion: We concluded that abnormalities of the 5-HT1A receptor function in the central nervous system of subjects with a diagnosis of PD are also mirrored in as an alteration in platelet activity. Measurements of platelet activity may be used as a tool for neuropsychiatric and psychopharmacological research and for studying how certain mental diseases and medications affect the central nervous system.

Keywords: 5-HT, thrombocyte, anxiety

\section{Introduction}

Serotonin (5-hydroxytryptamine [5-HT]) is well established as a neurotransmitter in the central nervous system (CNS), but it also plays diverse roles in the vascular system, including platelet aggregation and regulation of vascular tone. ${ }^{1}$ Researchers have suggested platelet activity is increased by emotional stress and hypothesized that the actions of stressors on platelets may be a primary trigger in such coronary events as myocardial infarction. ${ }^{2}$ Platelet uptake of 5-HT from the plasma is dependent on the 5-HT transporter, commonly regarded for its role in neurotransmitter reuptake in the CNS but also essential to the platelet plasma membrane. ${ }^{3}$ Platelet 5-HT has been extensively studied in psychiatry. Some studies have reported increased platelet 5-HT2A receptor density (expressed as maximum binding [Bmax]) in unipolar depression. Some have reported a positive correlation between platelet 5-HT2A receptor density and the Hamilton Depression Rating Scale suicidality item or loss of impulse control in suicide attempts. ${ }^{4-6}$

5 -HT is also important in the pathophysiology of pain in migraine, ${ }^{7,8}$ while the polymorphism of the 5-HT transporter gene appears to be associated with increased risk of migraine. ${ }^{9}$ Borgdorrf and Tangelder reviewed the evidence that release of platelet 
5-HT and platelet activation, by shear stress, may be important in migraine. ${ }^{10}$ They mentioned that platelets might be damaged or activated by a cardiovascular abnormality, eg, a symptomatic patent foramen ovale. Sarchielli et al suggested that the increased production of platelet-activating factor may account for persistent platelet activation during migraine crises. ${ }^{11}$ Ginkgolide B, a herbal constituent extract from Ginkgo biloba tree leaves, was considered as a promising pharmacological aid for the treatment of migraine in adult patients because of its modulation of the antiplatelet activating factor. ${ }^{12}$

The blood-brain relationship between platelets and the neuronal 5-HT transporter is supported by several lines of evidence, such as the correlation of platelet and synaptosomal reuptake, similar changes of human blood and cerebrospinal fluid 5-HT levels parallel changes of blood and brain 5-HT levels after administration of 5-HT-releasing drugs, and the association of depression with an increased risk of vascular events related to platelet dysfunction. ${ }^{13}$ Also, a meta-analysis reconfirmed initial reports of an association between platelet 5 -HT uptake and depression. ${ }^{14}$

Although many studies have been conducted on panic disorder (PD), the etiology of this debilitating disorder is still poorly understood. ${ }^{15}$ Recent research has linked abnormal 5-HT neurotransmission to the pathophysiology of PD. ${ }^{16}$ Catechol-O-methyltransferase (COMT) and 5-HT receptor $2 A$ (5-HTR2A) polymorphisms have been investigated for their possible role in PD, and Karaçetin et al found that the COMT Val158Met polymorphism was significantly associated with PD, in a Turkish population of PD patients. ${ }^{17}$

Platelets may reflect certain biochemical changes that occur in the brain when different mental conditions occur. ${ }^{18}$ The mean platelet volume (MPV), the accurate measure of platelet size, has been considered a marker and determinant of platelet function. Increased MPV may reflect either increased platelet activation or increased numbers of large, hyperaggregated platelets. ${ }^{19}$

This nonrandomized case-control study aimed to examine the MPV in patients with PD compared with healthy controls. It was hypothesized that subjects with PD have lower MPV levels compared with healthy controls. To our knowledge, this is the first study investigating the correlation of levels of MPV with PD.

\section{Methods}

Thirty-seven drug-free subjects aged 18 to 65 years who were diagnosed with PD, with or without agoraphobia, according to the Diagnostic and Statistical Manual of Mental Disorders, Fourth Edition (DSM-IV) criteria were included in the study. Forty-five subjects with similar sociodemographic characteristics and body mass index were included as a control group. Subjects included in the study were interviewed with the Structured Clinical Interview Diagnostic-I for DSM-IV. ${ }^{20}$ Patients with comorbid dysthymia, generalized anxiety disorder, or major depression were included if PD was judged as the principal diagnosis. Healthy control subjects with no personal history of psychiatric or physical disorder were hospital employees or were recruited through local advertisements. Sociodemographic data, height, body weight, and MPV were measured and recorded for each subject. Subjects who had seizure disorders, mental retardation, autistic disorder, organic brain damage, psychotic disorder, conduct disorder, hypertension, hypercholesterolemia, other acute or chronic physical illnesses, pregnancy, or a history of any drug use during the last month or smoking were excluded from the study.

The study was approved by the local medical ethics committee of Uskudar University, and written informed consent was obtained from each patient.

\section{Blood sampling}

Blood samples were drawn from each subject after a fasting period of 12 hours. In the fasting venous blood samples, collected with K3EDTA-containing sterile Vacutainer ${ }^{\mathrm{TM}}$ tubes, complete blood counts, including MPV, were determined using an Abbott CELL-DYN Sapphire ${ }^{\circledR}$ automated hematology analyzer (Abbott Laboratories, Abbott Park, IL, USA) with its own commercial kits. In order to measure MPV reliably and to minimize the potential influence of anticoagulant (ethylenediaminetetraacetic acid [EDTA]) on the MPV, blood samples were analyzed within 60 minutes after venipuncture. Platelet count and MPV were measured and recorded for each subject. The reference range for MPV was between 6.9-10.8 fL. All the blood samples were analyzed at the same laboratory (which participated in an external quality assurance program for the hemogram). The samples were analyzed daily, and only one batch was used for all the samples on each day, to avoid systemic inconsistency among batches. To assure quality, quality control samples were included in the run of the batches. The control samples confirmed the accuracy of results. Although automated hemogram analysis was used in this study, blood smear examination was also used to provide a visual confirmation of the automated instrument results.

\section{Statistics}

The data was analyzed using SPSS for Windows, Version 16.0 software (SPSS, Inc., Chicago, IL, USA). The differences 
in numerical variables between groups were analyzed by the $t$-test and Mann-Whitney $U$-test, and the differences in categorical variables were analyzed by chi-square analysis. Odds ratio and $95 \%$ confidence intervals (CIs) were used for the assessment of risk factors. A $P$-value less than 0.05 was considered as statistically significant.

\section{Results}

The PD group consisted of 21 females (56.8\%) and 16 males $(43.2 \%)$, and there were 25 females $(55.6 \%)$ and 20 males $(44.4 \%)$ in the control group. Mean ages were $34.06 \pm 9.5$ years in the PD and $35.8 \pm 10$ years in the control group. Mean body mass index was found to be $23.67 \pm 4.1 \mathrm{~kg} / \mathrm{m}^{2}$ and $23.64 \pm 2.9 \mathrm{~kg} / \mathrm{m}^{2}$ in the PD and control group, respectively. There were no statistically significant differences between groups, in terms of female/male ratio, age, or body mass index between the PD group and control group ( $P=0.91, P=0.82$, and $P=0.93$, respectively). The MPV was found to be significantly lower in the PD group compared with the control group $(8.8 \pm 0.9 \mathrm{fL}$ and $9.2 \pm 0.8 \mathrm{fL}$, respectively; $P=0.02$ ) (Table 1 and Figure 1). All the participants had MPV values in normal range of 6.9-10.8 fL.

\section{Discussion}

Because the CNS is difficult to access, peripheral platelet models are widely used as indicators of central 5-HT metabolism; moreover, they are known to reflect central serotonergic function. ${ }^{18,21}$ Platelets are useful models to study intracellular signal transduction events ${ }^{22}$ and have been widely used in psychiatry as a peripheral model of the serotonergic system

Table I The comparison of the panic disorder and healthy control groups, in terms of sociodemographic characteristics and hemogram results

\begin{tabular}{|c|c|c|c|}
\hline & $\begin{array}{l}\text { Panic disorder } \\
(n=37)\end{array}$ & $\begin{array}{l}\text { Healthy control } \\
(n=45)\end{array}$ & $P$ \\
\hline Age & $34.06 \pm 9.5$ & $35.8 \pm 10$ & 0.82 \\
\hline \multicolumn{4}{|l|}{ Sex \% (n) } \\
\hline Female & $56.8(2 I)$ & $55.6(25)$ & 0.91 \\
\hline Male & $43.2(16)$ & $44.4(20)$ & \\
\hline BMI kg/m² & $23.67 \pm 4.1$ & $23.64 \pm 2.9$ & 0.93 \\
\hline MPV fL & $8.8 \pm 0.9$ & $9.2 \pm 0.8$ & $0.02^{*}$ \\
\hline Hemoglobin g/dL & $13.5 \pm 0.7$ & $13.2 \pm 0.8$ & 0.54 \\
\hline RDW \% & $12.7 \pm 1.1$ & $12.5 \pm 0.9$ & 0.37 \\
\hline Platelet count $10^{9} / \mathrm{L}$ & $262 \pm 25.7$ & $247 \pm 45.6$ & 0.18 \\
\hline PDW fL & $12.5 \pm 2.7$ & $12.7 \pm 3.2$ & 0.37 \\
\hline WBC $10^{9} / \mathrm{L}$ & $8.6 \pm 1.1$ & $8.3 \pm 0.9$ & 0.14 \\
\hline
\end{tabular}

Notes: $* P<0.05$. Data expressed as mean $\pm S D$, unless otherwise stated. Abbreviations: BMI, body mass index; MPV, mean platelet volume; PDW, platelet distribution width; RDW, red cell distribution width; SD, standard deviation; WBC, white blood cell count.

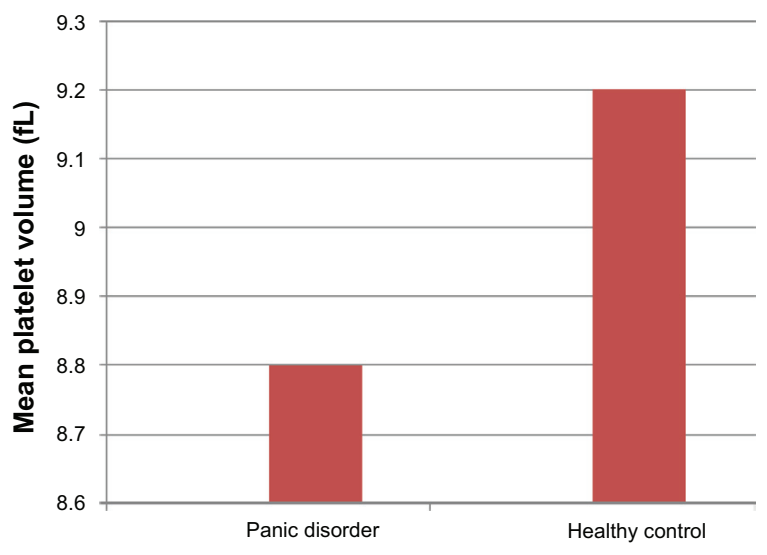

Figure I Bar chart of the panic disorder and healthy control groups in terms of MPV Abbreviation: MPV, mean platelet volume.

because they express the 5-HT2A receptors and 5-HT transporters identical to those present in the brain. ${ }^{23}$

Although three major parameters have been postulated as determinants of platelet volume, including age-dependent processes that can modify platelet size in the circulation, heterogeneity and maturity of the bone marrow megakaryocyte population, and peripheral size-related sequestration of platelets in storage pools, ${ }^{24}$ there is evidence that MPV is largely determined at or before the time of megakaryocyte fragmentation into platelets. ${ }^{25}$

There are a few studies that have focused on MPV in psychiatric populations. Ataoğlu and Canan reported that MPV was significantly higher than normal and that escitalopram treatment improved MPV, in patients with major depression. ${ }^{26}$ However, the mechanism of this increased platelet activity and increased MPV was not obvious. Hausberg et al reported increased sympathetic activity in patients with depression, ${ }^{27}$ and another study has shown that increased sympathetic activity can also cause higher MPV values. ${ }^{28}$ Thus, increased sympathetic activity might cause elevated MPV values, ${ }^{29}$ and this might be the reason for the increased MPV in patients with depression. Similarly Lande et $\mathrm{al}^{30}$ showed that MPV was significantly increased during adrenaline infusion, reflecting either swelling or shape change of platelets due to the activation of platelets or release of larger, activated platelets from the spleen. Researchers suggested that the sympathoadrenal activation may stimulate platelets via 2 -adrenoreceptor activation ${ }^{31}$ and that platelet activation, in turn, causes shape change and thereby increases MPV. ${ }^{32}$

In our research we found significantly lower MPV values in the PD group than in the healthy population. How does increased sympathoadrenal activation lead to decreased MPV? 
In platelets from patients affected by anxiety disorders, modifications in 5-HT transporter levels and activity, as well as abnormalities in 5-HT1A receptor functioning, have been described. ${ }^{33,34}$ Results of a study by Martini et al suggest that in platelets of PD patients, 5-HT was unable to induce significant phosphorylation of ERK 1 and 2, although their expression levels were not significantly different from healthy volunteers. ${ }^{35}$ Their results suggested that although no significant alterations of 5-HT1A or 5-HT2A receptor levels have been evidenced in PD, a significant increase in the basal phosphorylation state of these receptor subtypes occurred, likely suggesting specific alterations of the 5-HT receptor functional state in PD. Disordered 5-HT and decreased platelet activity may share a common pathophysiology in some mental disorders. Giret et $\mathrm{al}^{36}$ found decreased platelet 5-HT uptake and decreased platelet monoamine oxidase (MAO) activity in patients with major depression. In another study, patients receiving lithium therapy had increased platelet activity - lithium increases platelet 5-HT type 2 receptor sensitivity, helping to restore the abnormal 5-HT transport rate in patients with mood disorders. ${ }^{37} \mathrm{We}$ can speculate that the abnormal 5-HT metabolism in platelets reflect the abnormal function of platelets, which leads to decreased MPV, a marker and determinant of platelet function.

Despite the findings, some limitations should be noted for the present study. Firstly, the study sample was relatively small, making it difficult to draw definite conclusions. Although all analyses were done in a prespecified protocol, the sample size was not determined before the study start. We obtained sample size from previous studies with similar hypotheses. Secondly, we could not measure inflammatory markers, including the levels of IL-3, thyroid peroxidase (TPO), and in particular, IL-6, which are positively associated with MPV. In addition, this study did not examine either the levels of platelet reactivity or specific receptor pathways of platelet activation. But to the best of our knowledge, this is the first study investigating the MPV in PD.

\section{Conclusion}

Although 5-HT as a therapeutic target is widely recognized in the context of the CNS, it is also well established in amplifying platelet activation. MPV may give an indication of platelet activity. The findings of the present study suggest that MPV is decreased in the PD patients. Determining platelet function, which is universally available with routine automated hemograms, may serve as a "window to the brain".

\section{Disclosure}

The authors report no conflicts of interest in this work.

\section{References}

1. Vanhoutte PM. Platelet-derived serotonin, the endothelium, and cardiovascular disease. J Cardiovasc Pharmacol. 1991;17 Suppl 5:S6-S12.

2. Markovitz JH, Matthews KA. Platelets and coronary heart disease: potential psychophysiologic mechanisms. Psychosom Med. 1991;53(6):643-668.

3. Mercado CP, Kilic F. Molecular mechanisms of SERT in platelets: regulation of plasma serotonin levels. Mol Interv. 2010;10(4):231-241.

4. Bakish D, Cavazzoni P, Chudzik J, Ravindran A, Hrdina PD. Effects of selective serotonin reuptake inhibitors on platelet serotonin parameters in major depressive disorder. Biol Psychiatry. 1997;41(2):184-190.

5. Arora RC, Meltzer HY. Increased serotonin2 (5-HT2) receptor binding as measured by $3 \mathrm{H}$-lysergic acid diethylamide (3H-LSD) in the blood platelets of depressed patients. Life Sci. 1989;44(11):725-734.

6. Rao ML, Hawellek B, Papassotiropoulos A, Deister A, Frahnert C. Upregulation of the platelet Serotonin2A receptor and low blood serotonin in suicidal psychiatric patients. Neuropsychobiology. 1998;38(2):84-89.

7. Esposito M, Ruberto M, Pascotto A, Carotenuto M. Nutraceutical preparations in childhood migraine prophylaxis: effects on headache outcomes including disability and behaviour. Neurol Sci. 2012;33(6):1365-1368.

8. Panconesi A. Serotonin and migraine: a reconsideration of the central theory. J Headache Pain. 2008;9(5):267-276.

9. Liu H, Liu M, Wang Y, et al. Association of 5-HTT gene polymorphisms with migraine: a systematic review and meta-analysis. J Neurol Sci. 2011;305(1-2):57-66.

10. Borgdorff P, Tangelder GJ. Migraine: possible role of shearinduced platelet aggregation with serotonin release. Headache. 2012;52(8):1298-1318.

11. Sarchielli P, Alberti A, Coppola F, et al. Platelet-activating factor (PAF) in internal jugular venous blood of migraine without aura patients assessed during migraine attacks. Cephalalgia. 2004;24(8):623-630.

12. Carotenuto M, Esposito M. Nutraceuticals safety and efficacy in migraine without aura in a population of children affected by neurofibromatosis type I. Neurol Sci. 2013;34(11):1905-1909.

13. Scharinger $\mathrm{C}$, Rabl U, Kasess $\mathrm{CH}$, et al. Platelet serotonin transporter function predicts default-mode network activity. PLoS One. 2014;9(3): e92543.

14. Ellis PM, Salmond C. Is platelet imipramine binding reduced in depression? A meta-analysis. Biol Psychiatry. 1994;36(5):292-299.

15. Hamilton SP. Linkage and association studies of anxiety disorders. Depress Anxiety. 2009;26(11):976-983.

16. Maron E, Shlik J. Serotonin function in panic disorder: important, but why? Neuropsychopharmacology. 2006;31(1):1-11.

17. Karacetin G, Bayoglu B, Cengiz M, et al. Serotonin-2A receptor and catechol-O-methyltransferase polymorphisms in panic disorder. Prog Neuropsychopharmacol Biol Psychiatry. 2012;36(1):5-10.

18. Camacho A, Dimsdale JE. Platelets and psychiatry: lessons learned from old and new studies. Psychosom Med. 2000;62(3):326-336.

19. Park Y, Schoene N, Harris W. Mean platelet volume as an indicator of platelet activation: methodological issues. Platelets. 2002;13(5-6): 301-306.

20. First MB, Spitzer RL, Gibbon M, Williams JBW. Structured Clinical Interview for DSM-IV Axis I Disorders, Clinical Version (SCID-CV). Washington, DC: American Psychiatric Press, Inc.; 1996.

21. Lesch KP, Bengel D, Heils A, et al. Association of anxiety-related traits with a polymorphism in the serotonin transporter gene regulatory region. Science. 1996;274(5292):1527-1531.

22. Aharonovitz O, Granot Y. Stimulation of mitogen-activated protein kinase and $\mathrm{Na}+\mathrm{H}+$ exchanger in human platelets. Differential effect of phorbol ester and vasopressin. J Biol Chem. 1996;271(28):16494-16499. 
23. Cook EH, Fletcher KE, Wainwright M, Marks N, Yan SY, Leventhal BL. Primary structure of the human platelet serotonin 5-HT2A receptor: identify with frontal cortex serotonin 5-HT2A receptor. J Neurochem. 1994;63(2):465-469.

24. Jackson SR, Carter JM. Platelet volume: laboratory measurement and clinical application. Blood Rev. 1993;7(2):104-113.

25. Thompson CB, Love DG, Quinn PG, Valeri CR. Platelet size does not correlate with platelet age. Blood. 1983;62(2):487-494.

26. Ataoglu A, Canan F. Mean platelet volume in patients with major depression: effect of escitalopram treatment. J Clin Psychopharmacol. 2009;29(4):368-371.

27. Hausberg M, Hillebrand U, Kisters K. Addressing sympathetic overactivity in major depressive disorder. J Hypertens. 2007;25(10): 2004-2005.

28. Vizioli L, Muscari S, Muscari A. The relationship of mean platelet volume with the risk and prognosis of cardiovascular diseases. Int $J$ Clin Pract. 2009;63(10):1509-1515.

29. Durmaz T, Özdemir Ö, Keleş T, Bayram NA, Akçay M, Yeter E. Platelets and sympathetic activity in MI. Turk J Med Sci. 2009;39(2):259-265.

30. Lande K, Gjesdal K, Fønstelien E, Kjeldsen SE, Eide I. Effects of adrenaline infusion on platelet number, volume and release reaction. Thromb Haemost. 1985;54(2):450-453.
31. Hjemdahl P, Larsson PT, Wallén NH. Effects of stress and beta-blockade on platelet function. Circulation. 1991;84(6 Suppl):VI44-VI61.

32. Thompson CB, Eaton KA, Princiotta SM, Rushin CA, Valeri CR. Size dependent platelet subpopulations: relationship of platelet volume to ultrastructure, enzymatic activity, and function. Br J Haematol. 1982; 50(3):509-519.

33. Marazziti D, Rossi A, Dell'Osso L, et al. Decreased platelet $3 \mathrm{H}$-paroxetine binding in untreated panic disorder patients. Life Sci. 1999;65(25):2735-2741.

34. Lesch KP, Wolozin BL, Murphy DL, Reiderer P. Primary structure of the human platelet serotonin uptake site: identity with the brain serotonin transporter. J Neurochem. 1993;60(6):2319-2322.

35. Martini C, Trincavelli ML, Tuscano D, et al. Serotonin-mediated phosphorylation of extracellular regulated kinases in platelets of patients with panic disorder versus controls. Neurochem Int. 2004;44(8): 627-639.

36. Giret M, Launay JM, Dreux C, Zarifian E, Benyacoub K, Loo H. Modifications of biochemical parameters in blood platelets of schizophrenic and depressive patients. Neuropsychobiology. 1980;6(5):290-296.

37. Wood K, Swade C, Abou-Saleh MT, Coppen A. Apparent supersensitivity of platelet 5-HT receptors in lithium-treated patients. $J$ Affect Disord. 1985;8(1):69-72.
Neuropsychiatric Disease and Treatment

\section{Publish your work in this journal}

Neuropsychiatric Disease and Treatment is an international, peerreviewed journal of clinical therapeutics and pharmacology focusing on concise rapid reporting of clinical or pre-clinical studies on a range of neuropsychiatric and neurological disorders. This journal is indexed on PubMed Central, the 'PsycINFO' database and CAS,

\section{Dovepress}

and is the official journal of The International Neuropsychiatric Association (INA). The manuscript management system is completely online and includes a very quick and fair peer-review system, which is all easy to use. Visit http://www.dovepress.com/testimonials.php to read real quotes from published authors. 